\title{
ANALISA DAMPAK BENCANA ALAM PADA HUTAN DENGAN ALGORITMA C5.0 STUDI KASUS DINAS KEHUTANAN PROVINSI SUMATERA UTARA"
}

\section{Deviana Christiani Simanjutak}

Program Studi Teknik Informatika, STMIK Budi Darma, Medan, Indonesia

Email: deviana.medan2016@gmail.com

\begin{abstract}
Abstrak
Dinas Kehutanan Provinsi Sumatera Utara merupakan perangkat daerah yang melaksanakan urusan pemerintahan daerah Provinsi dan Kabupaten/Kota dibidang kehutanan. Pada Dinas Kehutanan Provinsi Sumatera Utara terdapat bencana alam. Bencana alam adalah peristiwa atau rangkaian peristiwa yang mengancam dan mengganggu kehidupan dan penghidupan masyarakat yang disebabkan, baik oleh faktor alam dan/atau faktor non alam maupun faktor manusia sehingga mengakibatkan timbulnya korban jiwa manusia, kerusakan lingkungan, kerugian harta benda, dan dampak psikologis. Di dalam bencana alam pada hutan mengalami kesulitan dalam mengidentifikasi data dalam menentukan besar atau kecil dampak bencana alam pada hutan. Penanganan dampak bencana alam ini bisa dilakukan dengan konsep data mining untuk menghasilkan informasi besar atau kecil dampak bencana alam yang sudah ada dan untuk membantu pengambilan keputusan. Untuk menghasilkan suatu keputusan maka digunakan algoritma C5.0, algoritma C5.0 adalah algoritma untuk memudahkan dalam menentukan besar atau kecil dampak bencana alam pada hutan yang terdapat pada Dinas Kehutanan Provinsi Sumatera Utara.
\end{abstract}

Kata kunci: Dinas Kehutanan, Data Mining, Algoritma C5.0

\begin{abstract}
The North Sumatra Provincial Forestry Service is a regional apparatus that carries out provincial and district / city regional government affairs in the forestry sector. In the North Sumatra Provincial Forestry Service there were natural disasters. Natural disasters are events or series of events that threaten and disrupt people's lives and livelihoods caused, both by natural and / or nonnatural factors as well as human factors, resulting in human casualties, environmental damage, property losses, and psychological impacts. In natural disasters in forests, it is difficult to identify data in determining the magnitude or impact of natural disasters on forests. Handling the impact of natural disasters can be done with the concept of data mining to produce information large or small the impact of existing natural disasters and to help decision making. To produce a decision, the C5.0 algorithm is used, the C5.0 algorithm is an algorithm to make it easier to determine the impact of natural disasters on forests in the North Sumatra Province Forestry.
\end{abstract}

Keywords: Forestry Service, Data Mining, Algoritma C5.O

\section{PENDAHULUAN}

Dinas Kehutanan Provinsi Sumatera Utara merupakan perangkat daerah yang melaksanakan urusan pemerintahan daerah Provinsi dan kabupaten/kota dibidang kehutanan. Hutan adalah paru-paru dunia dan sebuah kawasan yang ditumbuhi dengan lebat oleh pepohonan dan tumbuhan dan berfungsi sebagai penampung karbon dioksida, habitat hewan, modulator arus hidrologika, pelestari tanah, dan merupakan salah satu aspek biosfer bumi yang paling penting. Pada Dinas Kehutanan Provinsi Sumatera Utara terdapat bencana alam yang dapat merusak ekosistem pada hutan.

Bencana alam pada hutan yang tercatat di dinas kehutanan yaitu banjir,kebakaran hutan, tanah longsor dan luapan air sungai. Pada bencana alam pada hutan memiliki dampak bencana alam yang terjadi pada hutan yaitu adanya perubahan iklim, menurunnya keanekaragaman hayati, terganggunya siklus air, mengakibatkan kerugian ekonomi, mempengaruhi kualitas hidup serta meningkatnya potensi bencana alam.[1]

Di dalam dampak bencana alam pada hutan mengalami kesulitan dalam mengidentifikasi data dalam menentukan besar atau kecil dampak bencana alam pada hutan. Penanganan dampak bencana alam ini bisa dilakukan dengan konsep data mining untuk menghasilkan informasi besar atau kecil dampak bencana alam yang sudah ada dan untuk membantu pengambilan keputusan.

Untuk menghasilkan suatu keputusan maka digunakan algoritma C5.0. Algoritma C5.0 sebuah pohon keputusan untuk memudahkan dalam menentukan besar atau kecil dampak bencana alam pada hutan yang terdapat pada Dinas Kehutanan Provinsi Sumatera Utara. C5.0 dengan judul "Implementasi Algoritma C5.0 Dalam Klasifikasi Pendapatan Masyarakat Studi Kasus : Kelurahan Mesjid Kecamatan Medan Kota[2][1].

\section{TEORITIS}

\subsection{Data Mining}

Data mining, sering juga disebut Knowledge Discovery in Database (KDD), adalah kegiatan yang meliputi pengumpulan, pemakaian data historis untuk menemukan keteraturan, pola atau hubungan dalam set data berukuran besar. Keluaran dari data mining bisa dipakai untuk memperbaiki pengambilan keputusan di masa depan[3][4].

Dari defenisi-defenisi yang telah disampaikan, hal penting yang terkait dengan data mining adalah:

1. Data mining merupakan suatu proses otomatis terhadap data yang sudah ada.

2. Data yang akan diproses berupa data yang sangat besar. 
3. Tujuan data mining adalah mendapatkan hubungan atau pola yang akan mungkin memberikan indikasi yang bermanfaat[5][6].

Tetapi, tanpa penanganan yang seksama, perusahaan tidak dapat memanfaatkan investasinya di level yang lebih tinggi, maka dari itu sebelum benar-benar melakukan mining, perusahaan harus mengeluarkan sedikit effort lagi untuk realokasi dan pengadaan tools seperti layaknya seseorang yang melakukan penambangan.

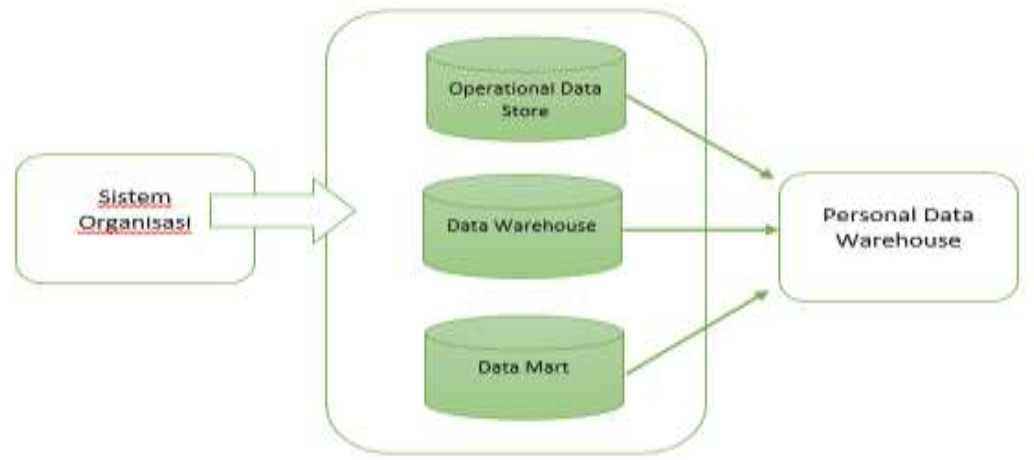

Gambar 1. Aliran Data Pada Pembentukan Data Warehouse

Sumber: Feri Sulianto dan Dominikus Juju, data meramalkan bisnis perusahaan mining,2010 [7]

Sebelum perusahaan membangun data warehouse dan data mart menggunakan sumber daya informasi internal dan mungkin juga eksternal, kelola data warehouse dengan mining tools akan meng-generate laporan-laporan orientasi strategi dan taktis, dengan view yang dimengerti para pemegang keputusan yang melibatkan pula statistik, pekerja ahli dan manager-manager yang ada setiap perusahaan.

\subsection{Algoritma C5.0}

Adalah salah satu algoritma klasifikasi data mining yang khususnya diterapkan pada teknik decision tree. C5.0 merupakan penyempurnaan algoritma sebelumnya yang dibentuk oleh Ross Quinlan padatahun 1987, yaitu ID3 dan C4.5. Dalam memilih atribut untuk pemecah objek dalam beberapa kelas harus dipilih atribut yang menghasilkan information gain paling besar. Adapun langkah-langkah Algoritma C5.0 sebagai berikut:

1. Pada tahap awal, tree digambarkan sebagai node tunggal yang mempresentasikan training set.

2. Jika sampel seluruhnya berisi kelas yang sama, maka node tersebut menjadi leaf dan dibeli dengan kelas tersebut.

3. Jika tidak, algoritma dengan menggunakan ukuran berbasis entropy(information gain) akan memilih table predictor yang akan memisahkan record ke dalam kelas-kelas individual. Variabel tersebut menjadi variabel tes atau keputusan pada node tersebut.

4. Cabang dikembangkan untuk tiap nilai yang diketahui dari variabel tes, dan sampel di partisi berdasarkan cabang tersebut.

5. Algoritma menggunakan proses yang sama secara rekrusif membentuk decision tree.

6. Partisi rekursif berakhir hanya ketika satu dari kondisi-kondisi berikut :

a. Seluruh record pada node tertentu memiliki kelas yang sama.

b. Tidak ada atribut yang tersisa pada record yang dapat dipartisi lebih lanjut. Dalam kasus ini suara mayoritas digunakan. Node tersebut menjadi leaf node dan dilabeli dengan kelas yang menjadi mayoritas dalam record yang ada.

c. Tidak ada record untuk cabang variabel tes. Dalam kasus ini, leaf berbentuk dengan mayoritas kelas sebagai label record tersebut.

Untuk menentukan akar dari pohon keputusan ditentukan oleh gain yang tertinggi, sebelum menemukan gain terdebih dahulu menghitung entropy keseluruhan dan entropy dari setiap atribut seperti yang terlihat pada rumus dibawah

$\operatorname{Entropy}(S) \sum_{i}^{n}=1-p i * \log 2$ pi

Keterangan :

$\mathrm{S}:$ himpunan kasus

A : atribut

$\mathrm{n}$ : jumlah partisi $\mathrm{S}$

pi : proporsi dari Si terhadap $\mathrm{S}$.

Setelah entropy diperoleh selanjutnya mentukan gain dari setiap atribut, dan mencari gain yang tertinggi untuk dijjadikan akar dari cabang pohon keputusan seperti rumus dibawah ini :

$\operatorname{Gain}(S, A)=\operatorname{Entropy}(S)-\sum_{i}^{n}=1 \frac{|\mathbf{S i}|}{|S|} * \operatorname{Entropy}(S i)$ 


\section{Keterangan:}

$\mathrm{S}:$ himpunan kasus

A : atribut

$\mathrm{n}$ : jumlah partisi atribut $\mathrm{A}$

|Si| : jumlah kasus pada partisi ke-i

$|\mathrm{S}|$ : jumlah kasus dalam $\mathrm{S}$

\section{ANALISA DAN PEMBAHASAN}

Data yang digunakan pada analisa ini adalah data bencana alam pada hutan yang diambil secara acak dari tahun 2017 dan tahun 2018 pada Dinas Kehutanan Provinsi Sumatera Utara. Data tersebut akan diolah menggunakan metode C5.0 yang menghasilkan suatu pohon keputusan untuk mengetahui besar atau kecil dampak bencana alam pada hutan.

Selanjutnya data tersebut juga diuji dengan menggunakan tools rapidminer yang fungsinya sama yaitu menghasilkan besar atau kecil dampak bencana alam pada hutan dalam pohon keputusan dan rule based presentation.

Kerangka pemikiran dalam pengembangan model sistem pada penelitian ini dapat digambarkan dalam suatu diagram alir penelitian seperti pada gambar 1. di bawah ini

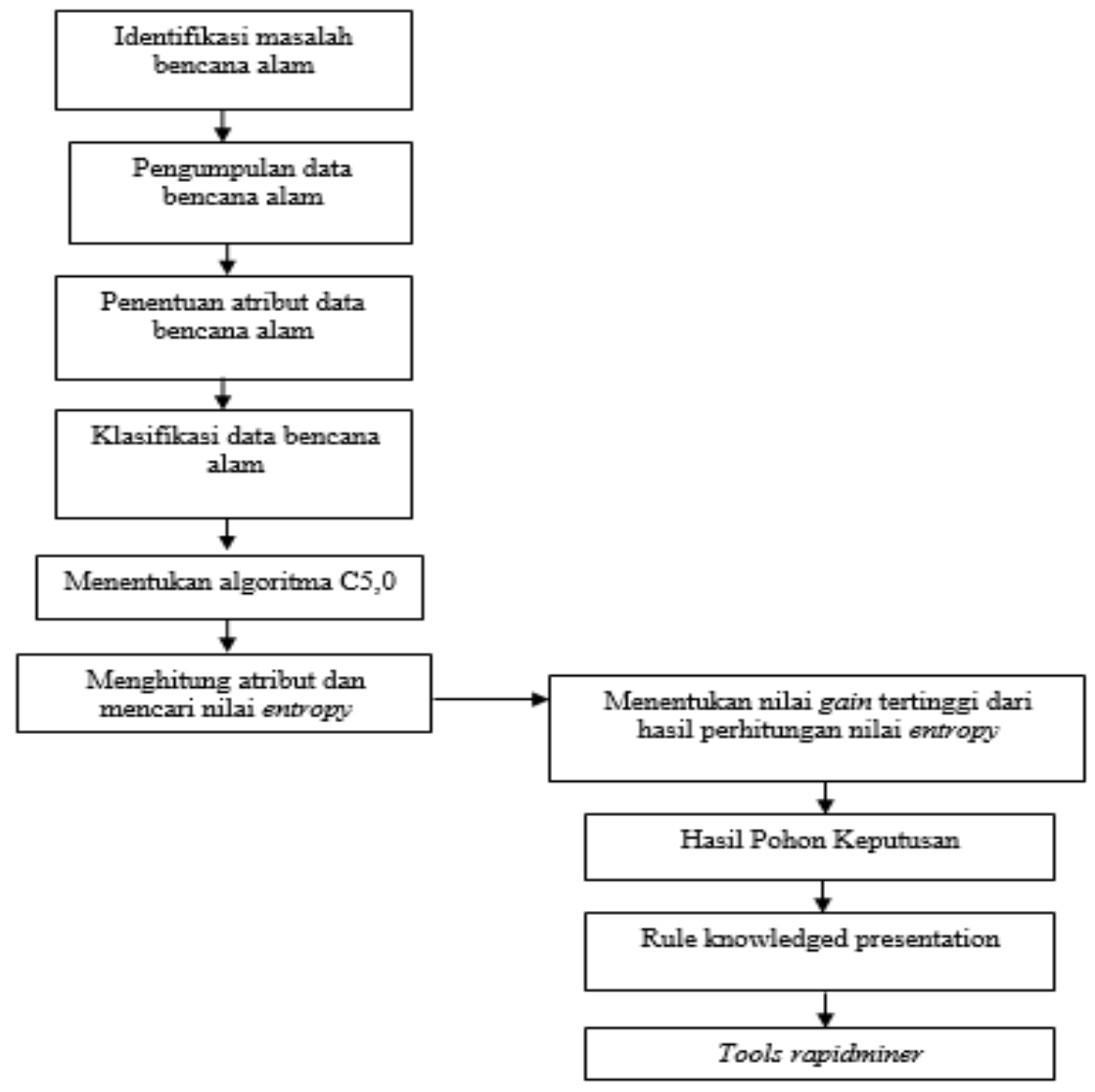

Gambar 2. Skema Sistem Kerja

Dalam bencana alam pada hutan ini, peneliti memperoleh data bencana alam dalam kurun waktu 2 tahun terakhir, yaitu tahun 2017 dan tahun 2018 Jumlah data tersebut yang diperoleh adalah 15 dan beserta atribut.

Tabel 1. Data bencana alam pada hutan di Dinas Kehutanan Provinsi Sumatera Utara

\begin{tabular}{|c|c|c|c|c|c|}
\hline No. & $\begin{array}{l}\text { Kecamatan Lokasi } \\
\text { Bencana }\end{array}$ & Jenis Bencana & $\begin{array}{l}\text { Jumlah Korban } \\
\text { Jiwa/KK }\end{array}$ & $\begin{array}{l}\text { Kerugian Akibat } \\
\text { Bencana }\end{array}$ & Penyebab \\
\hline 1. & Ulu Pungkut & Banjir & - & Rp.5.000.000 & Curah hujan yang tinggi \\
\hline 2. & Lingga Bayu & Banjir & - & $\operatorname{Rp} 8.000 .000$ & Tingginya curah hujan \\
\hline 3. & Batang Toru & $\begin{array}{l}\text { Kebakaran } \\
\text { hutan }\end{array}$ & 10 Jiwa & Rp.5.000.000 & Kemarau panjang \\
\hline 4. & $\begin{array}{l}\text { Pintu Pohan } \\
\text { Meranti }\end{array}$ & Tanah longsor & $8 \mathrm{KK} / 20$ Jiwa & Rp.8.000.000 & Pengikisan tanah \\
\hline 5. & Girsang Sipangan & Kebakaran & - & Rp. 5.000.000, & Kemarau panjang \\
\hline
\end{tabular}




\begin{tabular}{|c|c|c|c|c|c|}
\hline & Bolon & hutan & & & \\
\hline 6. & Barumun Tengah & Tanah longsor & - & Rp.5.000.000, & Pengikisan tanah \\
\hline 7. & Batang Natal & Banjir & $20 \mathrm{KK} / 60$ jiwa & $\begin{array}{l}\text { Rp.10.000.000 } \\
\text { 32Unit Rumah }\end{array}$ & $\begin{array}{l}\text { Kiriman debit air yang } \\
\text { tinggi dari hulu dan hujan }\end{array}$ \\
\hline 8. & Hamparan Perak & $\begin{array}{l}\text { Kebakaran } \\
\text { hutan }\end{array}$ & - & Rp.7.000.000 & Kemarau panjang \\
\hline 9. & Panai Hilir & $\begin{array}{l}\text { Kebakaran } \\
\text { hutan }\end{array}$ & - & Rp.8.000.000 & Kemarau panjang \\
\hline 10. & Pollung & Tanah longsor & $20 \mathrm{KK} / 40$ Jiwa & Rp. 10.000 .000 & Pengikisan tanah \\
\hline 11 & Panyabungan & Banjir & $\begin{array}{l}50 \mathrm{KK} / 100 \\
\text { Jiwa }\end{array}$ & Rp.30.000.000 & $\begin{array}{l}\text { Kiriman debit air yang } \\
\text { tinggi }\end{array}$ \\
\hline 12 & Padang Bolak & Tanah longsor & 24 KK / 93 Jiwa & Rp 10.000 .000 & Pengikisan tanah \\
\hline 13 & Kotanopan & Banjir & $\begin{array}{l}\text { 30KK / } 120 \\
\text { Jiwa }\end{array}$ & Rp.20.000.000 & $\begin{array}{l}\text { Kiriman debit air yang } \\
\text { tinggi dari hulu dan hujan }\end{array}$ \\
\hline 14 & Sosa & $\begin{array}{l}\text { Angin puting } \\
\text { beliung }\end{array}$ & - & Rp.6.000.000 & Hujan dan angin kencang \\
\hline 15 & Natal & Banjir & - & Rp. 5.000 .000 & Luapan air sungai \\
\hline
\end{tabular}

\section{Pre-Procecsing Data}

Dalam pre-procesing salah satu langkah yang digunakan adalah transformasi setiap nilai atribut yang sama kebentuk numerik sehingga mudah dilakukan untuk proses pemecahan masalah dan bentukan data dan sampelnya. Berikut ini pre-procesing yang dilakukan data ujinya yaitu :

1. Lokasi bencana, adalah lokasi bencana yang akan dijadikan acuan untuk dimasukkan kedalam data bencana alam.

2. Atribut adalah jenis bencana yang ada dalam data bencana alam.

3. Jumlah korban, untuk jumlah korban diklasifikasikan menjadi 2 (dua) jenis, yaitu :

a. Bernilai 1 apabila "statusnya" = Besar (Nilai $>10$ korban jiwa)

b. Bernilai 2 apabila "statusnya" = Kecil (Nilai $<10$ korban jiwa )

4. Atribut dampak dikelompokan ke dalam dua jenis, yaitu :

a. Jika tidak ada korban dan korban materi maksimal 5 juta, maka kategori dampaknya adalah "Kecil"

b. Jika ada korban jiwa maka kategori dampaknya adalah "Besar"

Setelah data dikelompokkan dan atribut-atribut penentu bencana alam maka tahap selanjutnya adalah klasifikasi data. Hasil data tabel dibawah ini:

Tabel 2. Data Klasifikasi Bencana Alam di Dinas Kehutanan Provinsi Sumatera Utara

\begin{tabular}{lllll}
\hline N0 & Letak Daerah Bencana & Jenis Bencana & Penyebab & Dampak \\
\hline 1 & Dekat Sungai & Banjir & Curah Hujan & Kecil \\
2 & Dekat sungai & Banjir & Curah Hujan & Kecil \\
3 & Daratan & Kebakaran hutan & Kemarau panjang & Besar \\
4 & Daratan & Tanah longsor & Pengikisan tanah & Besar \\
5 & Daratan & Kebakaran hutan & Kemarau panjang & Kecil \\
6 & Daratan & Tanah longsor & Kemarau panjang & Kecil \\
7 & Dekat Sungai & Banjir & Debit air yang tinggi & Besar \\
8 & Daratan & Kebakaran hutan & Kemarau panjang & Kecil \\
9 & Daratan & Kebakaran hutan & Kemarau panjang & Kecil \\
10 & Daratan & Tanah longsor & Pengikisan tanah & Besar \\
11 & Dekat sungai & Banjir & Debit air yang tinggi & Besar \\
12 & Daratan & Tanah longsor & Pengikisan tanah & Besar \\
13 & Dekat sungai & Banjir & Debit air yang tinggi & Besar \\
14 & Daratan & Angin puting beliung & Hujan dan angin kencang & Kecil \\
15 & Dekat sungai & Banjir & Luapan air sungai & Kecil \\
\hline
\end{tabular}

\section{Menentukan Atribut Akar}

Untuk pemilihan atribut sebagai akar, didasarkan pada nilai gain tertinggi dari atribut-atribut yang ada dengan menggunakan dua persamaan maka akan didapatkan entropy dan gain yang digunakan sebagai akar dalam membuat pohon keputusan.

A. Entropy Total

Untuk menggunakan dua persamaan Nilai entropy berdasarkan penilaian keseluruhan data berdasarkan tabel data decision bencana alam.

Diketahui :

Nilai Objek Keseluruhan $(\mathrm{Si})=15$

Nilai Atribut Hasil (Besar) $=7$ 
Nilai Atribut Hasil $($ Kecil $)=8$

$$
\begin{gathered}
\text { Entropy Total }=\left(-\frac{7}{15} * \log 2\left(\frac{7}{15}\right)\right)+\left(-\frac{8}{15} * \log 2\left(\frac{8}{15}\right)\right) \\
=0,996791632
\end{gathered}
$$

1. Menghitung nilai entropy letak daerah bencana

Nilai dekat sungai keseluruhan $(\mathrm{Si})=6$

Nilai atribut hasil (besar) $=3$

Nilai atribut hasil (kecil) $=3$

a. Entropy dekat sungai

$$
\begin{aligned}
= & \left(-\frac{3}{6} * \log 2\left(\frac{3}{6}\right)\right)+\left(-\frac{3}{6} * \log 2\left(\frac{3}{6}\right)\right) \\
= & 1
\end{aligned}
$$

Nilai daratan Keseluruhan $(\mathrm{Si})=9$

Nilai atribut hasil (besar) $=4$

Nilai atribut hasil $($ kecil $)=5$

b. Entropy daratan

$$
\begin{aligned}
& =\left(-\frac{4}{9} * \log 2\left(\frac{4}{9}\right)\right)+\left(-\frac{5}{9} * \log 2\left(\frac{5}{9}\right)\right) \\
= & 0,99107606
\end{aligned}
$$

2. Menghitung nilai entropy jenis bencana

Nilai banjir keseluruhan $(\mathrm{Si})=6$

Nilai atribut hasil (besar) $=3$

Nilai atribut hasil (kecil) $=3$

a. Entropy banjir

$$
\begin{aligned}
& =\left(-\frac{3}{6} * \log 2\left(\frac{3}{6}\right)\right)+\left(-\frac{3}{6} * \log 2\left(\frac{3}{6}\right)\right) \\
& =1
\end{aligned}
$$

Nilai kebakaran hutan keseluruhan $(\mathrm{Si})=4$

Nilai atribut hasil (besar) $=1$

Nilai atribut hasil (kecil) $=3$

b. Entropy kebakaran hutan

$$
\begin{aligned}
& =\left(-\frac{1}{4} * \log 2\left(\frac{1}{4}\right)\right)+\left(-\frac{3}{4} * \log 2\left(\frac{3}{4}\right)\right) \\
& =0.311278124
\end{aligned}
$$

Nilai tanah longsor keseluruhan $(\mathrm{Si})=4$

Nilai Atribut Hasil (Besar) $=3$

Nilai Atribut Hasil $($ Kecil $)=1$

c. Entropy tanah longsor

$$
\begin{aligned}
& =\left(-\frac{3}{4} * \log 2\left(\frac{3}{4}\right)\right)+\left(-\frac{1}{4} * \log 2\left(\frac{1}{4}\right)\right) \\
& =0.8112781242
\end{aligned}
$$

Nilai angin puting beliung keseluruhan $(\mathrm{Si})=1$

Nilai Atribut Hasil (Besar) $=0$

Nilai Atribut Hasil $($ Kecil $)=1$

d. Entropy angin puting beliung

$$
\begin{aligned}
& =\left(-\frac{0}{1} * \log 2\left(\frac{0}{1}\right)\right)+\left(-\frac{1}{1} * \log 2\left(\frac{1}{1}\right)\right) \\
& =0
\end{aligned}
$$

3. Menghitung nilai Entropy penyebab

Nilai curah hujan keseluruhan $(\mathrm{Si})=2$

Nilai Atribut Hasil $($ Besar $)=0$

Nilai Atribut Hasil (Kecil) $=2$

a. Nilai atribut Curah Hujan

$$
\begin{aligned}
& =\left(-\frac{0}{2} * \log 2\left(\frac{0}{2}\right)\right)+\left(-\frac{2}{2} * \log 2\left(\frac{2}{2}\right)\right) \\
& =0
\end{aligned}
$$

Nilai kemarau panjang keseluruhan $(\mathrm{Si})=4$

Nilai atribut hasil (besar) $=1$

Nilai atribut hasil (kecil) $=3$ 
b. Entropy kemarau panjang

$$
\begin{aligned}
& =\left(-\frac{1}{4} * \log 2\left(\frac{1}{4}\right)\right)+\left(-\frac{3}{4} * \log 2\left(\frac{3}{4}\right)\right) \\
& =0.311278124
\end{aligned}
$$

Nilai pengikisan tanah keseluruhan $(\mathrm{Si})=4$

Nilai Atribut Hasil $($ Besar $)=3$

Nilai Atribut Hasil $($ Kecil $)=1$

c. Entropy pengikisan tanah

$$
\begin{aligned}
& =\left(-\frac{3}{4} * \log 2\left(\frac{3}{4}\right)\right)+\left(-\frac{1}{4} * \log 2\left(\frac{1}{4}\right)\right) \\
& =0.8112781242
\end{aligned}
$$

Nilai debit air tinggi keseluruhan $(\mathrm{Si})=3$

Nilai Atribut Hasil (Besar) $=3$

Nilai Atribut Hasil $($ Kecil $)=0$

d. Entropy debit air yang tinggi

$$
\begin{aligned}
& =\left(-\frac{3}{3} * \log 2\left(\frac{3}{3}\right)\right)+\left(-\frac{0}{3} * \log 2\left(\frac{0}{3}\right)\right) \\
& =0
\end{aligned}
$$

Nilai hujan dan angin kencang keseluruhan $(\mathrm{Si})=1$

Nilai Atribut Hasil $($ Besar $)=0$

Nilai Atribut Hasil $($ Kecil $)=1$

e. Entropy hujan dan angin kencang

$$
\begin{aligned}
& =\left(-\frac{0}{1} * \log 2\left(\frac{0}{1}\right)\right)+\left(-\frac{1}{1} * \log 2\left(\frac{1}{1}\right)\right) \\
& =0
\end{aligned}
$$

Nilai luapan air sungai keseluruhan $(\mathrm{Si})=1$

Nilai Atribut Hasil (Besar) $=0$

Nilai Atribut Hasil $($ Kecil $)=1$

f. Entropy luapan air sungai

$$
\begin{aligned}
& =\left(-\frac{0}{1} * \log 2\left(\frac{0}{1}\right)\right)+\left(-\frac{1}{1} * \log 2\left(\frac{1}{1}\right)\right) \\
& =0
\end{aligned}
$$

B. Gain

\begin{tabular}{|c|c|c|c|c|c|c|c|}
\hline Node & & Keterangan & $\begin{array}{l}\text { Jumlah } \\
\text { Kasus (S) }\end{array}$ & $\begin{array}{l}\text { Besar } \\
\text { (B) }\end{array}$ & $\begin{array}{l}\text { Kecil } \\
(\mathrm{K})\end{array}$ & Entropy & Gain \\
\hline \multirow[t]{11}{*}{1} & TOTAL & & 15 & 7 & 8 & 0,996791632 & \\
\hline & Letak Daerah & & & & & & 0,002146 \\
\hline & Bencana & & & & & & \\
\hline & & Dekat sungai & 6 & 3 & 3 & 1 & \\
\hline & & Daratan & 9 & 4 & 5 & 0,99107606 & \\
\hline & Jenis Bencana & & & & & & 0,2974433 \\
\hline & & Banjir & 6 & 3 & 3 & 1 & \\
\hline & & Kebakaran hutan & 4 & 1 & 3 & 0,311278124 & \\
\hline & & Tanah longsor & 4 & 3 & 1 & 0,8112781244 & \\
\hline & & $\begin{array}{l}\text { Angin puting } \\
\text { beliung }\end{array}$ & 1 & 0 & 1 & 0 & \\
\hline & Penyebab & & & & & & 0,73012497 \\
\hline
\end{tabular}

1 Gain Letak daerah bencana

$$
\begin{aligned}
& \left.=0,996791632-\left(\left(\frac{6}{15} * 1\right)+\frac{9}{15} * 0,99107606\right)\right) \\
& =0,002146
\end{aligned}
$$

2.Gain Jenis bencana

$$
\begin{aligned}
& \left.=0,996791632-\left(\left(\frac{6}{15} * 1\right)\right)+\left(\left(\frac{4}{15}\right) * 0,311278124\right)\right)+\left(\left(\frac{4}{15}\right) * 0,811278124\right) \\
& \left.+\left(\left(\frac{1}{15}\right) * 0\right)\right) \\
& =0,2974433
\end{aligned}
$$

3.Gain Penyebab

$$
\begin{aligned}
& \left.\left.\left.\left.\left.=0,996791632-\left(\left(\frac{2}{15} * 0\right)\right)+\frac{4}{15} * 0,5\right)\right)+\left(\left(\frac{4}{15} * 0,5\right)+\frac{3}{15} * 0\right)\right)+\left(\left(\frac{1}{15} * 0\right)\right)+\frac{1}{15}\right) * 0\right) \\
& =0,73012497
\end{aligned}
$$

Setelah seluruh nilai Entropy dan Gain diperoleh dari sampel yang dimiliki, berikut ini adalah rekapitulasi perhitungan nilai Entropy dan Gainnya.

Tabel 3. Rekapitulasi Hasil 


$\begin{array}{lllll}\text { Curah hujan } & 2 & 0 & 2 & 0 \\ \text { Kemarau panjang } & 4 & 1 & 3 & 0,5 \\ \begin{array}{l}\text { Pengikisan tanah } \\ \begin{array}{l}\text { Debit air yang } \\ \text { tinggi }\end{array}\end{array} & 4 & 3 & 1 & 0,5 \\ \begin{array}{l}\text { Hujan dan angin } \\ \text { kencang }\end{array} & 1 & 3 & 0 & 0 \\ \begin{array}{l}\text { Luapan air sungai } \\ \text { Paja }\end{array} & 1 & 0 & 1 & 0 \\ \end{array}$

Tabel diatas menunjukkan bahwasanya kriteria penyebab memiliki nilai gain yang paling tinggi. Untuk fase selanjutnya adalah pembentukan tree (pohon keputusan). Berikut ini adalah tree dari rekapitulasi nilai entropy dan gainnya.

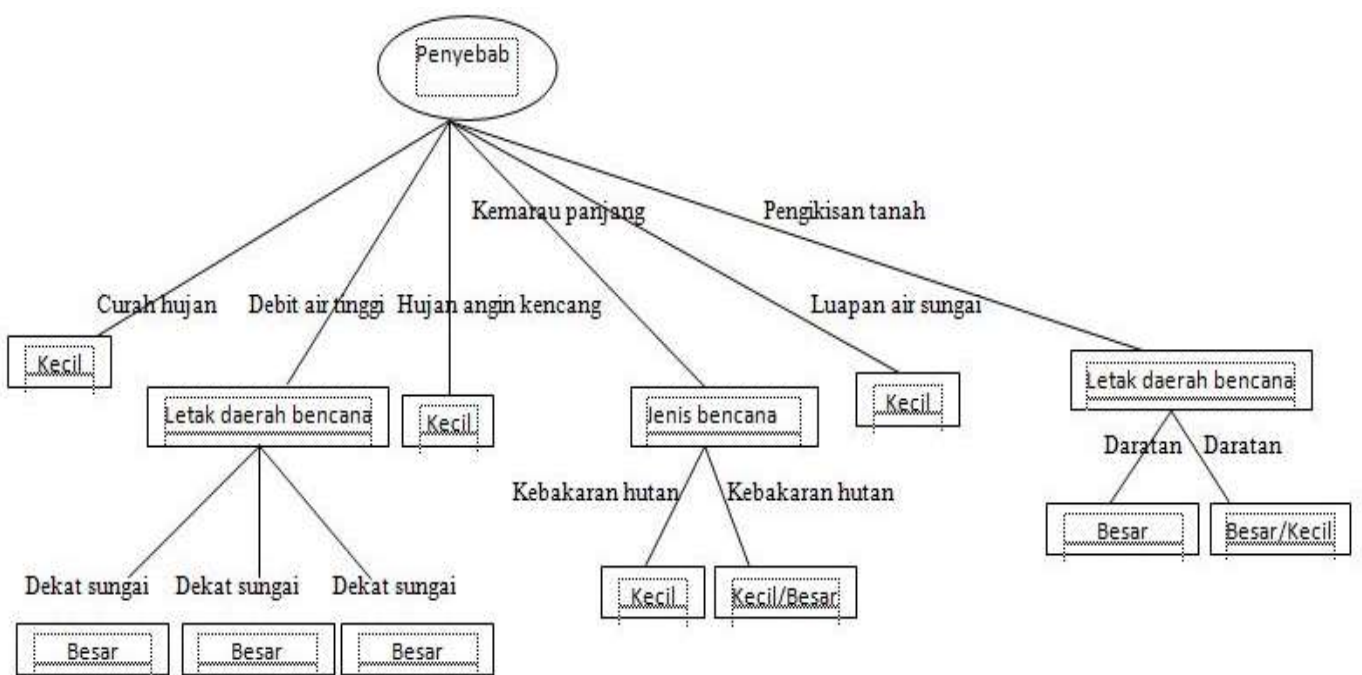

Gambar 3. Node Pohon Keputusan

Maka basis pengetahuan atau rule yang terbentuk yaitu :

1. Jika Penyebab = Curah hujan maka dampak $=$ Kecil.

2. Jika Penyebab $=$ Debit air tinggi dan Letak daerah bencana $=$ Dekat sungai maka dampak = Besar.

3. Jika Penyebab = Hujan dan angin kencang maka dampak = Kecil

4. Jika Penyebab = Kemarau panjang dan Jenis bencana = Kebakaran hutan maka dampak = Kecil/Besar.

5. Jika Penyebab $=$ Luapan air sungai maka dampak $=$ Kecil.

6. Jika Penyebab $=$ Pengikisan tanah dan Letak daerah bencana $=$ Daratan maka dampak $=$ Besar $/$ Kecil.

\section{KESIMPULAN}

Berdasarkan uraian pada bab-bab sebelumnya, maka penulis mengambil keputusan sebagai berikut :

1. Dengan mengunakan algoritma C5.0 dapat menganalisa dampak bencana alam.

2. Adapun hasil dari algoritma C5.0 yang memperoleh hasil dari analisa data bencana alam untuk menganalisa dampak bencana alam adalah jika penyebab = kemarau panjang maka dampak = besar

3. Hasil analisa dari bencana alam dapat mempermudah pihak Dinas Kehutanan Provinsi Sumatera Utara dalam analisa dampak bencana alam pada hutan.

\section{REFERENCES}

[1] E. Ndruru and R. Limbong, "Implementasi Data Mining Dalam Pengelompokan Jurusan yang Diminati Siswa SMK Negeri 1 Lolowa â€TM u menggunakan Metode Clustering," vol. 3, no. 2, pp. 107-113, 2018.

[2] A. C. Wijaya, N. A. Hasibuan, and P. Ramadhani, "IMPLEMENTASI ALGORITMA C5 . 0 DALAM KLASIFIKASI PENDAPATAN MASYARAKAT ( STUDI KASUS : KELURAHAN MESJID KECAMATAN MEDAN KOTA ),” vol. 13, 2018.

[3] B. Santosa, Data Mining, Teknik Pemanfaatan Data Untuk Keperluan Bisnis, 10th ed. Yogyakarta: Graha Ilmu, 2007.

[4] P. Biaya, P. Barang, P. Cv, E. Nias, and S. A. Hutabarat, "Implementasi Metode Vogel 's Approximation Method Pada," vol. 3, no. 1, pp. 12-15, 2018.

[5] F. T. Waruwu, E. Buulolo, E. Ndruru, K. Kunci, A. Apriori, and R. Penyakit, "KOMIK (Konferensi Nasional Teknologi Informasi dan Komputer) IMPLEMENTASI ALGORITMA APRIORI PADA ANALISA POLA DATA PENYAKIT MANUSIA YANG DISEBABKAN OLEH ROKOK."

[6] S. W. Sari and B. Purba, "Sistem Pendukung Keputusan Pemilihan Ketua Danru Terbaik Menggunakan Metode ARAS," pp. 291-300, 2019.

[7] Feri Sulianto dan Dominikus Juju, data meramalkan bisnis perusahaan mining, 19th ed. 2010. 